\title{
Development of a Self-Report Workbook for Identifying Cancer Patients Knowledge Expectations
}

\author{
Vaartio-Rajalin Heli ${ }^{1{ }^{*}}$, Leino-Kilpi Helena ${ }^{1}$ and Puukka Pauli ${ }^{2}$ \\ ${ }^{1}$ Department of Nursing Science, University of Turku, Finland \\ ${ }^{2}$ National Institute for Health and Welfare, Turku, Finland
}

"Corresponding author: Vaartio-Rajalin Heli, Researcher, Department of Nursing Science, University of Turku, Saukonkatu 10 a 3,20760 Piispanristi, Finland, Tel: +358 50 5742382; E-mail: heli.vaartio-rajalin@novia.fi

Received date: August 29, 2017; Accepted date: September 19, 2017; Published date: September 27, 2017

Copyright: ( 2017 Heli VR, et al. This is an open-access article distributed under the terms of the Creative Commons Attribution License, which permits unrestricted use, distribution, and reproduction in any medium, provided the original author and source are credited

\begin{abstract}
Patient-centeredness in patient education presupposes collaboration with the patient in the assessment of his/her knowledge expectations. In practice, there is no systematic approach to this assessment.

Purpose: To describe the development process of a self-report workbook intended to assist adult cancer patients to identify and communicate their knowledge expectations during the illness trajectory.

Design and methods: The workbook structure and content design was based on focus group interviews of cancer patients $(n=37)$, in-depth individual interviews $(n=16)$ and survey data in two countries $(n=332+483)$. The initial version of the workbook was validated in a sample of cancer patients $(n=91)$.

Findings: The usability of the workbook was found good: patients found it relevant, logical and easy to fill in. The content validity of the workbook was shown to be good: all ten subscales were rated as rather or very clear on scale 1-4. Content validity index for subscales (S-CVI) varied from 0.40 to 1.00 and content validity index on item level (I$\mathrm{CVI}$ ) from 0.76 to 0.94 . Internal consistency was established as good: Cronbach's alphas varied from 0.58 to 0.96 .
\end{abstract}

Conclusion: From the patients' perspective, the self-report workbook is a promising aid for identifying individual patients' perspectives to patient education and its outcomes during the illness trajectory.

Keywords: Patient-centered care; Education; Self-report workbook; Cancer

\section{Introduction}

Patient education should be patient-centered and empowering. The patients should be provided with individual, contextually targeted education that focuses on what patients themselves can do at home and in their everyday life prior to, during and after medical treatments [1]. In patient-centered education, the patients are engaged in active dialogue with health care professionals to continuously define their knowledge expectations and in terms of the choice of educational activities and evaluation of their comprehension during and after the education. Furthermore, patient-centered education includes a relevant and accountable response to the identified knowledge expectations, the inter-professional coordination of educational interventions and the analysis of patient education outcomes from the perspectives of both the patient and the health care personnel.

Several studies have focused on cancer patients' informational needs. A need assessment has traditionally referred to health care providers' perceptions of what kind of information should be introduced to the patients [2]. A learning need can also be seen as a reflection of discrepancy between what a person desires to know and the current knowledge he/she has [3]. Due to this conceptual duality, in this study, the term knowledge expectation is applied. Expectations can be defined as values that reflect importance of a particular topic [4] or as recognition that one's knowledge is inadequate to satisfy a goal within the situation that an individual finds him/herself at a specific point in the time [5]. Recognition of such inadequateness is a vital step in the process of empowerment, enabling people to recognize their strengths and personal power with assistance of information [6]. Patients' own knowledge expectations guide the content of education, and as a result of education, positive cognitive outcomes can be seen [7]. In this paper, the focus is on the development process of a new self-report workbook intended to assist adult cancer patients to identify and communicate their knowledge expectations during the illness trajectory.

\section{Background}

Empowering patient education in oncologic context calls for sensitivity to cancer patients' individual knowledge expectations, sensitivity to the critical moments of cancer trajectory for the proper timing of patient education, and collaboration with the patient in the assessment of his/her knowledge expectations during the illness trajectory.

Empowering patient education has been identified [8] to integrate six types of knowledge required by patients to manage their health problems: bio-physiological (knowledge about illness, symptoms, treatment and complications), functional (mobility, rest, nutrition and body hygiene), experiential (emotions and hospital experiences), social (families, other patients and patient unions), ethical (rights, duties, 
participation in decision-making and confidentiality) and financial (costs and financial benefits). These knowledge domains have been validated in several studies in different contexts $[9,10]$. In oncologic context, the patients' $(\mathrm{n}=915)$ knowledge expectations seem to follow these domains, and the patients stressed personalized, resourcepromoting process and action knowledge, which vary during the illness trajectory due to several demographical, situational and clinical factors.

The critical moments of cancer trajectory according to the patients themselves are the following:

- Waiting for a cancer diagnosis,

- Receiving a cancer diagnosis,

- Participating in the care planning,

- Waiting for cancer management to begin,

- Receiving cancer care,

- Discussing or revising a care plan,

- Receiving palliative care,

- Coming to an end of cancer management,

- Rehabilitation phase,

- Having check-ups

By continuously encouraging the cancer patients to analyze and recognize their knowledge expectations at these critical moments of illness trajectory, the cancer care personnel can offer empowering education intended to help individuals to identify and find their own skills and strengths [1]. In other words, the focus is shifted from the delivery of general information to patient-centered, empowering education and from illness to actual possibilities, active participation in decision-making and self-care. However, the professionals always have an ethical obligation to provide the obligatory information, e.g. about the potential risks, even when patients are unwilling to formulate their knowledge expectations.

There are some instruments focusing on adult cancer patients' informational needs. In the European Organisation for Research and Treatment of Cancer questionnaire [11], the focus is on biological and medical issues, as is also the case for the Patient Information Need Questionnaire [12]. In the Toronto Informational Needs Questionnaire, the subscales include psychosocial items as well [13], but no financial or ethical issues. The existing instruments concerning cancer patients' informational needs focus on a preconceived categorization of information that patients "need" to know, rather than their own knowledge expectations. The Information Styles Questionnaire [14] focuses on information satisfaction. Furthermore, all these instruments are applied in a certain situation, usually at the beginning of the illness trajectory, apart from the Patient Learning Needs Scale [15], which is applied at discharge. It would be more patient-centered to repeatedly self-report and reassess the patients' knowledge expectations during the course of their illness trajectory and to base the patient education on the contextual knowledge expectations.

Due to limitations of current instruments, a self -report workbook concerning cancer patients' actual knowledge expectations during the whole illness trajectory was to be developed. A self-report workbook is not only a means to activate and empower cancer patients in their education, but also a tool to assess the perceived quality of education from the viewpoint of patients during the patient education process and to develop an interdisciplinary approach to patient education. With such an individualized aid, the patients would be encouraged to regulate their own patient education, and to be involved in decisionmaking concerning their care. The health care personnel, in turn, could use the data for guidance in patient education planning, coordination and evaluation [16].

\section{Purpose}

In this paper, the aim is to describe the development process of a self-report workbook intended to assist adult cancer patients to identify and communicate their knowledge expectations during the critical moments of their illness trajectory.

The research question is: How to develop a relevant content and a clear structure for a self-report workbook to enable adult cancer patients identify and communicate their knowledge expectations during the critical moments of their illness trajectory?

The workbook development process is a part of a research project aimed to provide a model of empowering patient education for cancer patients during their illness trajectory.

\section{Design and Methods}

The self-report workbook development process was implemented among samples of actual and former cancer patients, which can be seen as a patient-centered, empowering approach [17].

The general principles of research ethics [18] were applied. Ethical approval was granted by relevant hospital ethical committees, as was the permission for data collection from the local cancer association. In each data collection phase, the informants were asked to sign a written informed consent.

\section{Self-report workbook development}

In order to constitute a relevant content and structure for a selfreport workbook, data collection was performed in four phases. These data collection and analysis phases have been reported on earlier in other papers, and therefore are not described here in detail.

First, in order to identify adult cancer patients' knowledge expectations during their whole illness trajectory and to identify the critical moments of patient education, focus group interviews $(n=10$ groups) were conducted in a purposive sample of oncologic patients $(n=37)$ at different stages of illness trajectory. These patients had different primary cancer sites, e.g. prostate cancer, testicular cancer, breast cancer, lung cancer, lymphoma, melanoma, leukemia, colorectal cancer, bladder cancer, kidney cancer, thyroid cancer or glioma. The respondents were recruited from a Finnish university hospital (with two oncologic wards, two outpatient clinics) with special expertise in oncologic treatment. The focus group also included former cancer patients with experience in peer support; they were recruited through the local cancer association. The data thus collected served as the basis for the content of empowering patient education in oncologic context, i.e., the items of the self-report workbook.

Second, from the same focus group sample, some informants $(n=16)$ that were willing to further express their individual experiences participated in an individual in-depth interview for the purpose of identifying significant factors related to the patients' knowledge expectations, i.e., factors they found as altering their individual knowledge expectation variations during the illness trajectory. The data served as the basis of the structure of the self-report workbook, 
i.e., the subscales describing the critical moments of the cancer trajectory in relation to empowering patient education.

Third, in order to test the validity of the knowledge expectation categories obtained from the interview data sets in relation to critical moments of the cancer trajectory, a survey was conducted using the structured Expected Knowledge of Hospital Patients instrument [3]. The EKHP ${ }^{\circ}$ is a 59 -item instrument that measures the six types of earlier mentioned empowering knowledge, the actual clinical symptoms and emotional distress. The instrument has been validated in several studies. The survey data for this study were collected from two university hospitals (with four oncologic wards and four outpatient clinics) in Finland $(n=332)$ and for cultural comparison, from one university hospital in Spain $(n=483)$. Also in these samples, the patients showed a wide range of primary cancer sites (gastroenterological, neurological, hematological, nephrological, etc.).

Fourth, the usability and internal consistency of the self-report workbook was explored. Obtaining evidence for content validity is a process that judges the adequacy of the specific content sampling and the adequacy with which the content is reflected in the instrument items [19]. The usability, relevance and clarity of the initial version of the self-report workbook were explored in a sample of actual and former cancer patients recruited from three organizations: two cancer clinics at two hospitals in Finland, and a local cancer association. The respondents, considered as being experts in cancer patients' education due to their first-hand experience of cancer [20], were recruited with the assistance of ward sisters and the secretary of the local cancer association. In terms of an expert sample, 2 to 20 experts with different perspectives on the focus area of the research are considered as representative enough [21]. The respondents rated the relevance of items on a scale from 1 to $4 \quad(1=$ not important at all; $2=$ not very important; 3 =rather important; $4=$ very important), and correspondingly, the clarity of items on a scale from 1 to $4(1=$ not clear at all; $2=$ not very clear; $3=$ rather clear; $4=$ very clear). Because there has been criticism concerning the inter-rater mean CVI (Content Validity Index) and its ability to capture the relevance of a set of items instead of single items, both item-level (I-CVI) and subscale-level (S-CVI) content validity indices [22] were calculated. In addition, the internal consistency of each subscale was assessed using Cronbach's alpha (minimum 0.70). We also explored whether cancer patients in different parts of illness trajectory differ with regard to their perceptions of knowledge expectations.

\section{Description of the self-report workbook}

The four data sets described above constituted the foundation for the content (patients' knowledge expectations during illness trajectory) and structure (the critical moments of illness trajectory) for a selfreport workbook intended to identify and communicate cancer patients' knowledge expectations during the whole illness trajectory. The six types of knowledge expectations [3] were not used as such in the workbook - the self-reported workbook is totally based on the analysis of actual and former cancer patients' knowledge expectations - but they were applied for comparison purposes during the workbook development process.

The self-report workbook contains 24 pages (size B5) with 10 subscales, which are named according to the critical moments of cancer trajectory. These comprise a total of 133 knowledge expectation items and possible further specifying sub-questions. For example, Subscale 3 "Participating in the care planning" contains the knowledge expectation item "How do the different cancer management alternatives affect (me)...?" with specifying sub-questions "...my physical capacity/my working capacity/my appearance". In addition, at every page of the workbook, there is room for patient's notes (the specific issues they want to know about within the knowledge expectation theme) (Table 1 ).

\begin{tabular}{|c|c|c|c|c|c|c|}
\hline $\begin{array}{l}\text { My situation right now } \\
\text { Subscales and subcategories }\end{array}$ & $\begin{array}{l}\text { My current } \\
\text { knowledge } \\
\text { expectations } \\
\text { Items }\end{array}$ & Cronbach's alpha & $\mathbf{N}$ & $\begin{array}{l}\text { Mean for } \\
\text { importance } \\
\text { (Scale 1-4) }\end{array}$ & $\begin{array}{l}\text { Median for } \\
\text { importance } \\
\text { (Scale 1-4) }\end{array}$ & $\begin{array}{l}\text { SD for } \\
\text { importance }\end{array}$ \\
\hline $\begin{array}{l}\text { Subscale } 1 \\
\text { Waiting for a cancer diagnosis } \\
\text { Subcategories: }\end{array}$ & & 0.78 & 88 & 3.38 & 3.46 & 0.42 \\
\hline $\begin{array}{l}\text { I have noticed some symptoms in myself and I } \\
\text { wonder if they can mean cancer }\end{array}$ & 3 items & & & $3.58-3.74$ & 4.00 & $0.66-0.70$ \\
\hline $\begin{array}{l}\text { I have contacted a physician and I am preparing } \\
\text { myself for diagnostic examinations }\end{array}$ & 5 items & & & $2.68-3.76$ & $2.00-4.00$ & $0.60-1.05$ \\
\hline I am waiting for examination results & 3 items & & & $2.48-3.61$ & $3.00-4.00$ & $0.73-1.09$ \\
\hline I get to hear my results & 2 items & & & $3.86,3.86$ & $4.00,4.00$ & 0.35 .0 .38 \\
\hline Subscale 2 & & 0.58 & 91 & 3.65 & 3.75 & $0.34-0.90$ \\
\hline Receiving a cancer diagnosis & & 0.92 & 90 & & & \\
\hline $\begin{array}{l}\text { Subcategory: } \\
\text { I understand that I have a cancer }\end{array}$ & 4 items & & & $2.90-3.90$ & $3.00-4.00$ & \\
\hline Subscale 3 & & & & & & \\
\hline $\begin{array}{l}\text { Participating in to the care planning } \\
\text { Subcategory: }\end{array}$ & 33 items & & & 3.14 & 3.21 & 0.48 \\
\hline I am participating to my care plan & & & & $2.19-3.78$ & $2.00-4.00$ & $0.52-1.06$ \\
\hline Subscale 4 & & 0.9 & 88 & 3.33 & 3.41 & 0.55 \\
\hline
\end{tabular}


Citation: Heli VR, Helena LK, Pauli P (2017) Development of a Self-Report Workbook for Identifying Cancer Patients Knowledge Expectations. J Nurs Care 6: 425. doi:10.4172/2167-1168.1000425

Page 4 of 7

\begin{tabular}{|c|c|c|c|c|c|c|}
\hline $\begin{array}{l}\text { Waiting for a cancer management to begin. } \\
\text { Subcategories: } \\
\text { I am waiting for my cancer management to } \\
\text { begin } \\
\text { I meet my own nurse. }\end{array}$ & $\begin{array}{l}5 \text { items } \\
18 \text { items }\end{array}$ & & & $\begin{array}{l}3.12-3.53 \\
2.87-3.80\end{array}$ & $\begin{array}{l}3.00-4.00 \\
3.00-4.00\end{array}$ & $\begin{array}{l}0.67-1.04 \\
0.48-1.17\end{array}$ \\
\hline $\begin{array}{l}\text { Subscale } 5 \\
\text { Receiving cancer care } \\
\text { Subcategories: } \\
\text { I am receiving chemotherapy/radiation therapy/ } \\
\text { hormonal treatment/stem cell transplantation/ } \\
\text { interferon } \\
\text { Discussing or revising a care plan } \\
\text { Subcategory: } \\
\text { I discuss my care plan with my oncologist/my } \\
\text { nurse } \\
\text { Subscale } 7 \\
\text { Receiving palliative care } \\
\text { Subcategory: } \\
\text { I am at ward due to side-effects }\end{array}$ & 31 items & 0.96 & 88 & $\begin{array}{l}3.22-3.79 \\
3.41 \\
2.87-3.30 \\
3.40 \\
3.22-3.58\end{array}$ & $\begin{array}{l}3.66 \\
3.00-4.00 \\
3.50 \\
3.00-4.00\end{array}$ & $\begin{array}{l}0.51-0.96 \\
0.60 \\
0.48-1.17 \\
0.61 \\
0.79-0.82\end{array}$ \\
\hline $\begin{array}{l}\text { Subscale } 8 \\
\text { Coming to an end of cancer management } \\
\text { Subcategory: } \\
\text { My functional capacity is normalizing, I feel I am } \\
\text { myself again } \\
\text { Subscale } 9 \\
\text { Rehabilitation phase } \\
\text { Subcategory: } \\
\text { I am having rehabilitation }\end{array}$ & . & 0.60 & 88 & $\begin{array}{l}3.42 \\
0.34-3.84 \\
3.29 \\
3.06,3.52\end{array}$ & $\begin{array}{l}3.55 \\
2.00-4.00 \\
3.50 \\
3.00,4.00\end{array}$ & $\begin{array}{l}0.55 \\
0.37-1.24 \\
0.76 \\
0.76,0.98\end{array}$ \\
\hline $\begin{array}{l}\text { Subscale } 10 \\
\text { Having check-ups } \\
\text { Subcategory: } \\
\text { I am having check-ups }\end{array}$ & 6 items & 0.91 & 89 & $\begin{array}{l}3.67 \\
3.67-3.89\end{array}$ & $\begin{array}{l}4.00 \\
4.00\end{array}$ & $\begin{array}{l}0.59 \\
0.54-0.62\end{array}$ \\
\hline
\end{tabular}

Table 1: Structure of the instrument; items and descriptive statistics.

With the self-report workbook, adult cancer patients are assumed to identify their knowledge expectations with reference to their current illness trajectory phase and communicate their knowledge expectations to cancer nurses, radiology nurses and oncologists. While reading the items (knowledge expectations) and rating them (by marking the suitable option and date: 'I expect to know about this item', 'I have received patient education about this item', 'I have understood this item'), the patients actually can decide what they want to learn about and when (empowerment) and evaluate whether the patient education has been patient-centered

\section{Results}

The four data sets concerning the different knowledge expectations, the significant factors affecting patients' knowledge expectations and the critical moments of cancer patient education seem to provide a relevant content and structure for the self-report workbook. In the fourth data set, actual and former cancer patients $(n=91)$ supported the usability, content and internal consistency of the initial version of the workbook. The majority of the respondents (76\%) were over 51 years of age (range 19-83, Md 60.5), female (67\%), married (56\%) and currently receiving cancer management $(72 \%)$, such as chemotherapy or radiation therapy (Table 2).

\begin{tabular}{|l|l|l|l|}
\hline Variable & $\mathbf{N}(\%)$ & Variable & $\mathbf{N}(\%)$ \\
\hline Age & & Family situation & \\
\hline $18-30$ years & $2(2)$ & Single & $14(17)$ \\
\hline $31-40$ years & $3(3)$ & Living together & $9(10)$ \\
\hline $41-50$ years & $6(7)$ & Married & $49(56)$ \\
\hline
\end{tabular}




\begin{tabular}{|c|c|c|c|}
\hline $51-60$ years & $30(35)$ & Divorced & $8(9)$ \\
\hline 61-70ears & $36(34)$ & Widow & $7(18)$ \\
\hline $71-80$ year & $12(13)$ & & \\
\hline over 81 years & $2(2)$ & & \\
\hline Gender & & Number of children & $\mathrm{N}(\%)$ \\
\hline Male & $29(33)$ & 0 & $1(1.5)$ \\
\hline Female & $60(67)$ & 1 & $19(27)$ \\
\hline Education & & 2 & 27 (39) \\
\hline Basic/comprehensive education & $24(27)$ & 3 & $16(23)$ \\
\hline General secondary education & $23(26)$ & 4 & $5(7)$ \\
\hline Vocational education & $24(27)$ & 5 & $1(1.5)$ \\
\hline University education & $18(20)$ & 6 & $1(1.5)$ \\
\hline My situation right now & $\mathrm{N}(\%)$ & & \\
\hline Waiting for a cancer diagnosis & $0(0)$ & & \\
\hline Receiving a cancer diagnosis & $2(2)$ & & \\
\hline Participating in to the care planning & $1(1)$ & & \\
\hline Waiting for a cancer management to begin & $4(4.5)$ & & \\
\hline Receiving cancer care & $63(72)$ & & \\
\hline Receiving palliative care & $1(1)$ & & \\
\hline Coming to an end of cancer management & $5(6)$ & & \\
\hline Having check-ups & $12(14)$ & & \\
\hline
\end{tabular}

Table 2: Demographic data on the respondents in data four, $n=91$.

The importance of the mean and median values for each subscale and for every item within the subscales were analyzed and a value $>3.00$ (on scale 1-4) was established as a criterion for a subscale or item to be included in the next version of the workbook. The content validity of the workbook appears to be rather good; the inter-rater mean I-CVI varied from 0.76 to 0.94 . The subscales helped the respondents to identify their own position in terms of the illness trajectory, and they found the items easy to understand. Thus, the clarity of the subscales (from 3.29 to 3.69 on scale 1-4) and items (all $>3$ on scale 1-4) was established as good. To be included in the next version of the self-report workbook, importance values exceeding 3.0 were required for the mean and median values for every subscale and every item within the subscales. Thus, altogether 13 items from four different subscales (including 9 items from Subscale 3) were identified as items to be excluded from the next version. The internal consistency of each subscale was assessed using Cronbach's alpha. Cronbach's alphas for the ten subscales varied from 0.58 to 0.96 . Eight subscales of ten exceeded the minimum level of 0.70 , suggesting that the workbook reflected adequately the content of adult cancer patients' knowledge expectations [19].

In the fourth data set, some subscales were found to relate with the importance ratings. Respondents who had just received their diagnosis or were waiting for their cancer treatments to begin (i.e., Subscales 2 and $4 ; 6.5 \%$ of the sample) perceived all subscales, except for palliative care (Subscale 7), as very important. On item level, the items related to cancer diagnosis, prognosis and treatment alternatives, as well as timetable issues and self-care means, were perceived as very important (mean $>3.70$ ). Those respondents, who were currently receiving cancer management $(72 \%)$, rated retrospectively the same subscales as very important as the newly diagnosed respondents did, but they already had a focus on the future, i.e., coming to an end of cancer management (Subscale 8), rehabilitation (Subscale 9) and check-ups (Subscale 10). Respondents identifying themselves as being in the rehabilitation phase $(7 \%)$ were more often than the others interested in the cancer association, social worker services and the effectiveness of their cancer management methods. Those respondents who already had an outpatient role with check-ups (14\%) still considered examination results, cancer status (Subscales 1 and 2) and symptoms related to cancer management as well as palliative care (Subscales 6 and 7) as very important. These findings validate, in some degree, the critical moments of illness trajectory established in the first three data sets, but, due to the small sample size, not at a statistically significant level. 


\section{Discussion and Conclusion}

This study describes the development process of a self-report workbook designed to assist adult cancer patients to identify and communicate their knowledge expectations to cancer nurses, radiology nurses and oncologists during their whole illness trajectory. The study is a part of a project with a goal to develop a model for empowering patient education for cancer patients.

In cancer care, the focus of patient education traditionally seems to be on the patients assumed information needs of the patients [11-13], but in this study, we prefer to use the term patients' knowledge expectations. Accordingly, the earlier assessment methods that are concerned with cancer patients' informational needs do not meet the criteria of subjectivity and a dialogue, nor do they let health care professionals evaluate whether cancer patients find the patient education understandable and useful. The application of the new selfreport workbook facilitates dialogical analysis of patients' knowledge expectations and comprehension, thus providing opportunities to discuss the patients' perspectives in the light of care coordination and quality management [16] during the whole illness trajectory.

Our patient-centered workbook demonstrates a promise of serving as contextual, empowering self-report aid of adult cancer patients' knowledge expectations during the whole illness trajectory. The respondents in our four data sets wanted to know about not only the current phase of their illness trajectory, but also about the future. The key feature of our workbook is that the patients can choose what they actually want to know about at the given moment, and what not yet i.e., both process and outcome empowerment. With the assistance of individual patient analysis and tailored patient education, the traditional information becomes knowledge for that particular individual [7] and has the potential to empower him/her to sustain life control during the cancer management process and to promote personal behaviors and understanding, self-care resources, as well as to take an action in relation to self-determination.

In all four data sets, the respondents represented well the incidence of different cancer types in Finland and in Northern Europe [23,24]. The samples were quite homogenous, i.e., the majority of respondents were in the active cancer management phase or the check-up phase. However, they considered that they were able to recall well the earlier phases of their illness trajectory and to analyze them. In addition, the data sets included respondents with a longer time elapsed from their own cancer experience, currently serving as peer support for actual cancer patients. Their participation allowed for the validation of the critical moments of patient education and the knowledge expectations of those patients who were in the beginning of illness trajectory.

\section{Limitations}

However, there are some limitations in this self-report workbook development process. All the four data sets were collected among samples of actual and former cancer patients. The sampling strategies were based on voluntariness, so it may suffer from a self-selection bias. Oncologic nurses or oncologists were not included in these four data collection phases, so the workbook is validated only from the patients' perspective. Cancer patients can use this self-report workbook in identification of their knowledge expectations, but if they don't remember or dare to show the results of the self-report to the nurses or oncologists, they can neither regulate the content or the timing of patient education nor evaluate its outcomes. Therefore, the practical usefulness of the self-report workbook is to be validated from the perspectives of patients and nurses as well as oncologists in an intervention study in clinical oncologic setting during 2017.

\section{Conflict of Interest}

The authors declare that there is no conflict of interest.

\section{References}

1. Chen J, Mullins CD, Novak P, Thomas SB (2016) Personalized strategies to activate and empower patients in health care and reduce health disparities. Health Educ Behav 43: 25-34.

2. Cramer Bertram C (2008) Informational needs and the experiences of women with abnormal Papanicolaou smears. J Am Acad Nurse Pract 20: 455-462.

3. Leino-Kilpi H, Johansson K, Heikkinen K, Kaljonen A, Virtanen H, et al. (2005) Patient education and health-related quality of life. Surgical hospital patients as a case in point. J Nurs Care Qual 20: 307-316.

4. Zywiel MG, Mahomed A, Gandhi R, Perruccio AV, Mahomed NN (2013) Measuring expectations in orthopaedic surgery: A systematic review. Clin Orthop Relat Res 471: 3446-3456.

5. Ormandy P (2001) Defining information needs in health-assimilating complex theories derived from information science. Health Expect 14: 92-104.

6. Gottlieb LN (2012) Strengths-based nursing care: Health and healing for person and family, Springer, New York.

7. Ryhänen AM, Rankinen S, Siekkinen M, Saarinen M, Korvenranta H, et al. (2012) The impact of an empowering internet based breast cancer patient pathway program to breast cancer patients' knowledge: A randomized control trial. Pat Educ Couns 88: 224-231.

8. Leino-Kilpi H, Luoto E, Katajisto J (1998) Elements of empowerment and MS patients. J Neurosci Nurs 18: 116-123.

9. Siekkinen M, Kesänen J, Vahlberg T, Pyrhönen S, Leino-Kilpi H (2015) Randomized controlled trial of the effect of e-feedback on knowledge about radiotherapy of breast cancer patients in Finland. Nurs Health Sci 17: 97-104.

10. Salonen A, Ryhänen A, Leino-Kilpi H (2014) Educational benefits of Internet and computer-based programmes for prostate cancer patients: A systematic review. Patient Educ Couns 91: 10-19.

11. Arraras JL, Wright S, Greimel E, Holzner B, Kuljanic-Vlasic K, et al. (2004) Development of questionnaire to evaluate the information needs of cancer patients: The EORTC questionnaire. Patient Educ Couns 54: 235-241.

12. Mesters van den Borne B, Maarten De B, Pruyn J (2001) Measuring information needs among cancer patients. Patient Educ Couns 43: 253-262.

13. Galloway S, Graydon J, Harrison D, Evans-Boyd B, Palmer-Wickham S, et al. (1997) Informational needs of women with a recent diagnosis of breast cancer: Development and initial testing of a tool. J Adv Nurs 25: 1175-1183.

14. Thomas R, Kaminski E, Stanton E, Williams M (2004) Measuring information strategies in oncology - developing an information satisfaction questionnaire. Eur J Cancer Care (Engl) 13: 65-70.

15. Galloway SC, Bubela N, McKibbon A, McCay E, Ros E (1993) Perceived information needs and effect of symptoms on activities after surgery for lung cancer. Can Oncol Nurs J 3: 116-119.

16. Luckett T, Butow PN, King MT (2009) Improving patient outcomes through the routine use of patient-reported data in cancer clinics: Future directions. Psychooncology 18: 1129-1138.

17. Barr PJ, Scholl I, Bravo P, Faber MJ, Elwyn G, McAllister M (2015) Assessment of patient empowerment - A systematic review of Measures. PloS ONE 10.

18. World Medical Association. Declaration of Helsinki - ethical principles for medical research involving human subjects. 
Citation: Heli VR, Helena LK, Pauli P (2017) Development of a Self-Report Workbook for Identifying Cancer Patients Knowledge Expectations. J Nurs Care 6: 425. doi:10.4172/2167-1168.1000425

Page 7 of 7

19. Beck CT, Gable RK (2001) Ensuring content validity: An illustration of the process. J Nurs Meas 9: 201-215.

20. Armstrong TS, Cohen MZ, Eriksen L, Cleeland C (2005) Content validity of self-report measurement instruments: An illustration from the development of the brain tumor module in the M.D. Anderson Symptom Inventory. Oncol Nurs Forum 32: 669-676.

21. Grant JS, Davis LL (1997) Selection and use of content experts for instrument development. Res Nurs Health 20: 269-274.
22. Polit E, Beck CT (2006) The content validity index: Are you sure you know what's being reported? Critique and recommendations. Res Nurs Health 29: 489-497.

23. Nordcan 2013.

24. SEOM (2013) Sociedad española de oncología médica. 